\title{
Water vapor transport in the lower mesosphere of the subtropics: a trajectory analysis
}

\author{
T. Flury ${ }^{1}$, S. C. Müller ${ }^{1, *}$, K. Hocke ${ }^{1}$, and N. Kämpfer ${ }^{1}$ \\ ${ }^{1}$ Institute of Applied Physics, University of Bern, Sidlerstrasse 5, 3012 Bern, Switzerland \\ *now at: METEOTEST, Fabrikstrasse 14, 3012 Bern, Switzerland \\ Received: 10 June 2008 - Published in Atmos. Chem. Phys. Discuss.: 18 July 2008 \\ Revised: 16 October 2008 - Accepted: 27 October 2008 - Published: 10 December 2008
}

\begin{abstract}
The Institute of Applied Physics operates an airborne microwave radiometer AMSOS that measures the rotational transition line of water vapor at $183.3 \mathrm{GHz}$. Water vapor profiles are retrieved for the altitude range from 15 to $75 \mathrm{~km}$ along the flight track. We report on a water vapor enhancement in the lower mesosphere above India and the Arabian Sea. The measurements took place on our flight from Switzerland to Australia and back in November 2005 conducted during EC- project SCOUT-O3. We find an enhancement of up to $25 \%$ in the lower mesospheric $\mathrm{H}_{2} \mathrm{O}$ volume mixing ratio measured on the return flight one week after the outward flight. The origin of the air is traced back by means of a trajectory model in the lower mesosphere and wind fields from ECMWF. During the outward flight the air came from the Atlantic Ocean around $25 \mathrm{~N}$ and $40 \mathrm{~W}$. On the return flight the air came from northern India and Nepal around $25 \mathrm{~N}$ and $90 \mathrm{E}$. Mesospheric $\mathrm{H}_{2} \mathrm{O}$ measurements from Aura/MLS confirm the transport processes of $\mathrm{H}_{2} \mathrm{O}$ derived by trajectory analysis of the AMSOS data. Thus the large variability of $\mathrm{H}_{2} \mathrm{O}$ VMR during our flight is explained by a change of the winds in the lower mesosphere. This study shows that trajectory analysis can be applied in the mesosphere and is a powerful tool to understand the large variability in mesospheric $\mathrm{H}_{2} \mathrm{O}$.
\end{abstract}

\section{Introduction}

Water vapor plays a key role in atmospheric processes. In the troposphere it acts as a strong greenhouse gas and is responsible for weather mechanisms such as convection, cloud for-

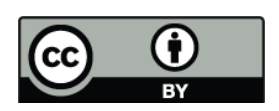

Correspondence to: T. Flury (thomas.flury@iap.unibe.ch) mation and latent heat release. In the stratosphere $\mathrm{H}_{2} \mathrm{O}$ contributes to radiative cooling and plays a role in ozone depletion chemistry by the formation of polar stratospheric clouds. In the lower mesosphere as well as in the stratosphere water vapor can be used as a tracer for atmospheric transport. Further it is involved in the buildup of polar mesospheric clouds also known as noctilucent clouds at the summer mesopause.

The $\mathrm{H}_{2} \mathrm{O}$ volume mixing ratio (VMR) decreases from a few percent in the tropical troposphere to a few parts per million in the mesosphere. The measurement over 4 orders of magnitude is difficult to be achieved by one single measurement technique. We use ground-based and airborne microwave remote sensing for the retrieval of $\mathrm{H}_{2} \mathrm{O}$ VMR in the middle atmosphere (Deuber et al., 2005; Müller et al., 2008). A typical water vapor profile measured on 16 November 2005 at $35 \mathrm{~N}$ and $30 \mathrm{E}$ by our airborne microwave radiometer AMSOS (Airborne Microwave Stratospheric Observing System) is shown in Fig. 1: $\mathrm{H}_{2} \mathrm{O}$ VMR decreases exponentially in the troposphere to reach a minimum at the so called hygropause which is slightly above the tropopause. In the stratosphere $\mathrm{H}_{2} \mathrm{O}$ VMR increases again due to the formation from oxidation of methane and reaches a maximum at the stratopause and lower mesosphere. Finally solar Lyman$\alpha$ flux determines the photolysis of water vapor in the upper mesosphere. In the lower mesosphere and upper stratosphere, the continuum absorption of water vapor occurs in the domain of the $\mathrm{O}_{2}$ Schumann-Runge bands.

The chemical lifetime of water vapor in the middle atmosphere is of the order of years in the lower stratosphere and months in the lower mesosphere (Brasseur and Solomon, 2005), allowing for water vapor to be used as a tracer in the upper stratosphere and lower mesosphere. The use of a trajectory model provides a dynamical understanding of local water vapor variability.

Published by Copernicus Publications on behalf of the European Geosciences Union. 


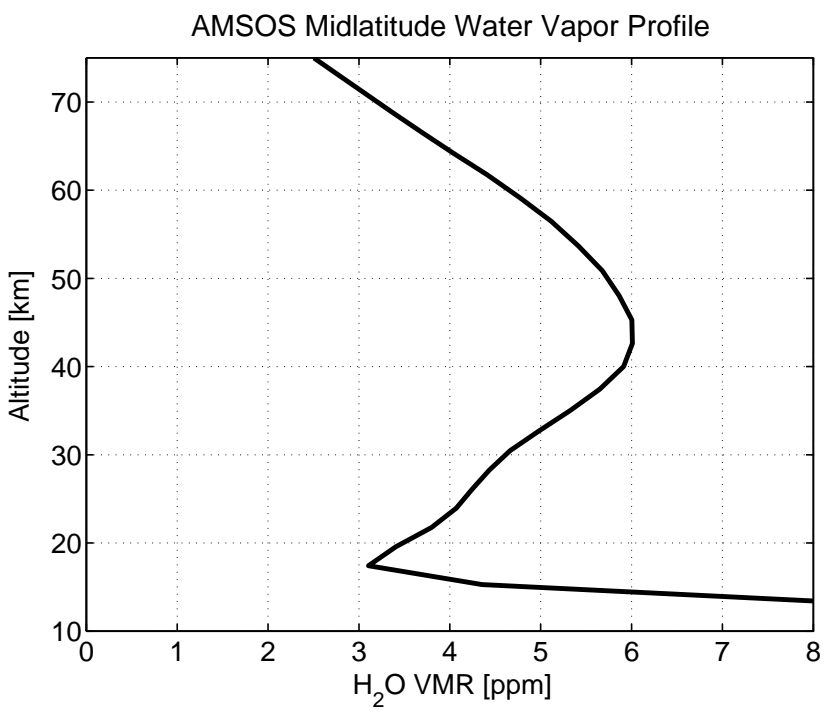

Fig. 1. A measured AMSOS midlatitude water vapor profile in November 2005 above the Mediterranean with the typical dry hygropause at $18 \mathrm{~km}$ and a middle atmospheric local maximum around the stratopause at $45 \mathrm{~km}$.

The strong eastward and westward winds in the mid latitude middle atmosphere are a consequence of the pole to pole circulation which is mainly due to latitudinal temperature differences and to gravity wave breaking at the mesopause, which decelerates the zonal flow by the deposition of angular momentum. The change of the zonal flow induces a meridional transport according to the conservation of angular momentum (Shepherd, 2000). Fig. 2 shows the ECMWF windfield at $60 \mathrm{~km}$ altitude for the northern hemisphere on 15 November. The strong eastward wind at mid latitudes changes direction around equinox and becomes westward in summer. The middle atmospheric circulation leads to reduced water vapor VMR in the mesosphere of the winter pole due to descent motion from the mesopause and enhanced water vapor in the summer pole mesosphere due to upward transport of $\mathrm{H}_{2} \mathrm{O}$ rich air. Such a mesospheric distribution is shown in Fig. 3 as measured by NASA's Microwave Limb Sounder (MLS) (Waters et al., 2006) on the Aura satellite for $60 \mathrm{~km}$ altitude.

\section{Instrument and profile retrieval}

AMSOS is a total-power radiometer based on a conventional uncooled heterodyne receiver using a Schottky diode mixer as reported by Vasic et al. (2005). The instrument measures the thermal emission of the pressure broadened water vapor rotational transition line at $183.3 \mathrm{GHz}$, which allows the retrieval of $\mathrm{H}_{2} \mathrm{O}$ altitude profiles. Two digital Fast Fourier Transform spectrometers resolve the spectral line with a channel resolution of $61 \mathrm{kHz}$ and $12 \mathrm{kHz}$ (Müller et al., in press). The main result of AMSOS are water vapor pro-

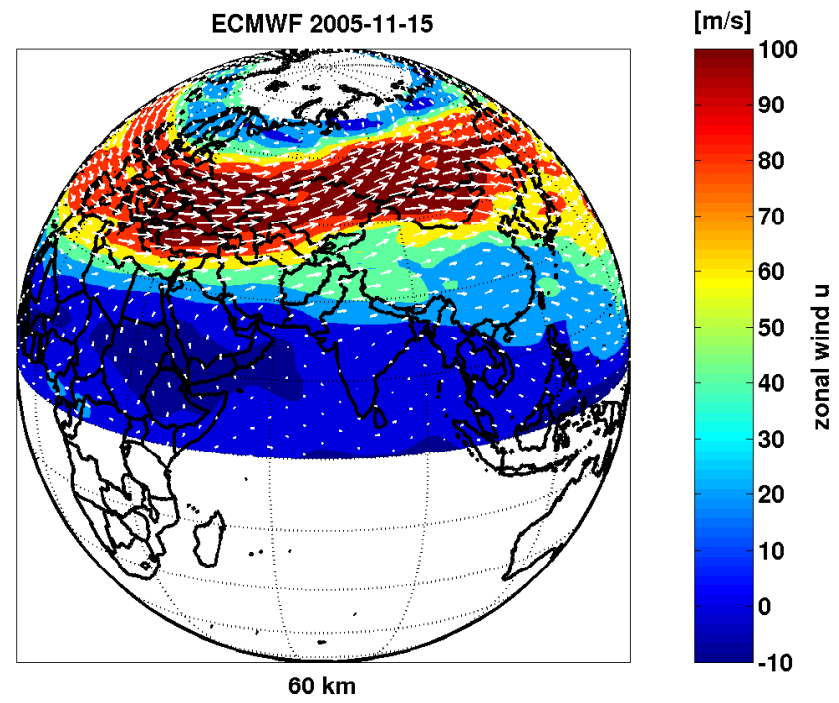

Fig. 2. ECMWF modeled wind at $60 \mathrm{~km}$ on 15 November 2005 , 06:00 UTC for the Northern Hemisphere. The strong midlatitude jet is visible in red. Zonal wind is represented in color and vectors represent horizontal wind direction in arbitrary units. Above India the zonal wind is close to zero and negative (westward).

files between 15 and $75 \mathrm{~km}$ from polar regions to the tropics as reported by Feist et al. (2007) and Müller et al. AMSOS is flown on board a Swiss Airforce Learjet and was operated once a year since 1998. The line of sight of the instrument is perpendicular to the flight direction with an elevation angle of 20 degrees. Such a geometry facilitates the data analysis for the mesospheric wind retrieval which is another product of AMSOS as reported by Flury et al. (2008).

AMSOS measures continuously during flights with a horizontal resolution of 30 to $80 \mathrm{~km}$. The horizontal resolution depends on the integration time of spectra for the retrieval of one profile, which is 6 minutes for the here shown spectra acquired with the narrow band FFT spectrometer. Hence a horizontal resolution of $80 \mathrm{~km}$ results (average speed of Learjet: $800 \mathrm{~km} / \mathrm{h}$ ). The vertical resolution is between 10 and $15 \mathrm{~km}$ for the upper stratosphere and lower mesosphere (Müller et al., 2008).

Narrowband spectrometers with a high channel resolution allow a retrieval of water vapor for mesospheric altitudes while broadband spectrometers are able to provide information about the upper troposphere and lower stratosphere. This fact is due to the analysis of the pressure broadened line: The better the line center is resolved the more information one gets about the mesosphere whilst the broader the spectrum is the more information one gets out of the wings of the spectrum, which are assigned to the lower part of the middle atmosphere. Water vapor profiles are retrieved by an optimal estimation method (Rodgers, 2000) which is implemented in the inversion software package ARTS/QPack (Buehler et al., 2005; Eriksson et al., 2005) 

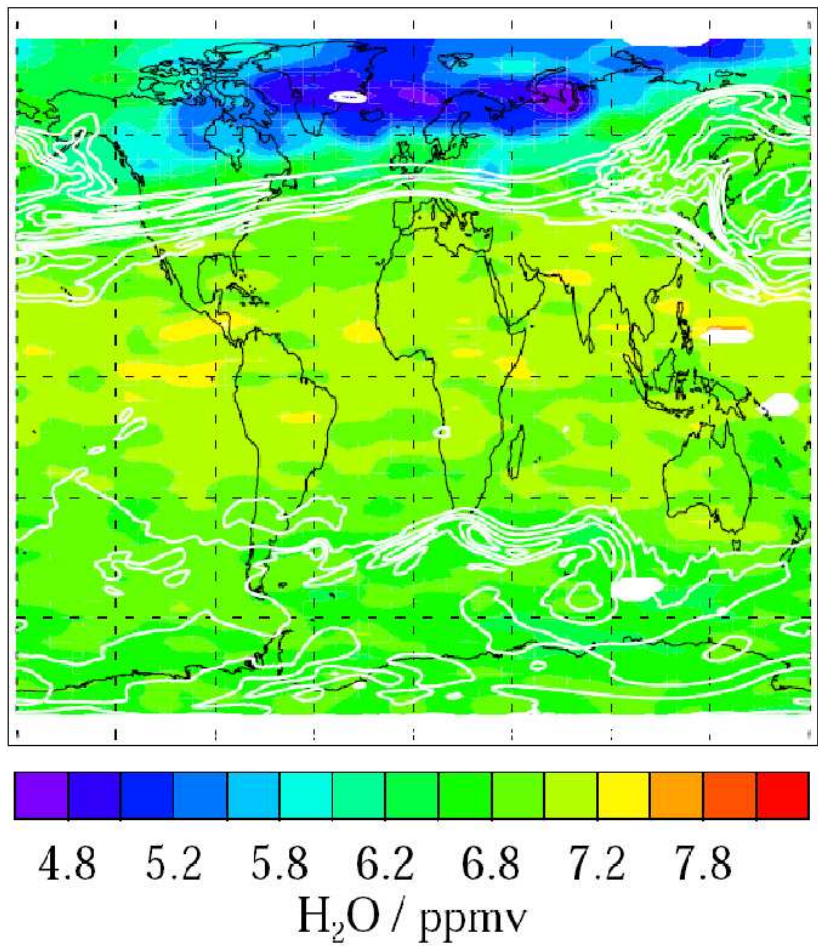

Fig. 3. Aura MLS water vapor at $60 \mathrm{~km}$ on November 5 th. The low values in the Arctic and the higher values in the Antarctic region are a sign of the middle atmospheric circulation. Air parcels for the trajectory study started in the dark green region near the Canary islands. Maps available on http://mls.jpl.nasa.gov/data/gallery.php.

\section{Results and discussion}

A total of 300 mesospheric profiles were retrieved for the SCOUT-O3 flight campaign along the flight track shown in Fig. 4. All the retrieved $\mathrm{H}_{2} \mathrm{O}$ profiles are plotted in Fig. 5 as a function of latitude for the outward (upper plot) and return flight (lower plot). The flight route was chosen identically for both flights. $\mathrm{H}_{2} \mathrm{O}$ VMR is between 3 and $8 \mathrm{ppm}$ in the altitude range $45 \mathrm{~km}$ to $75 \mathrm{~km}$. The water vapor distribution in the middle atmosphere has a pronounced latitudinal dependence as can be seen in Fig. 3, where a global map of mesospheric water vapor at $60 \mathrm{~km}$ is shown measured by Aura/MLS. We only measure single profiles at a specific time on the flight track, it is thus very important to understand atmospheric dynamics leading to the measured distribution.

There is a significant difference between the outward and return flight above the Arabian Sea and India, marked by two dashed rectangles in Fig. 5, which starts at $60 \mathrm{E}$ and $23 \mathrm{~N}$ and ends at $70 \mathrm{E}$ and $20 \mathrm{~N}$ and also between the first and last part of the flight over the Mediterranean Sea ( 45 N-35 N, 10 E-30 E) highlighted by two solid rectangles. AMSOS measured between $15 \%$ and $25 \%$ more water vapor above $55 \mathrm{~km}$ on the return flight over India and the Arabian Sea one week after the outward flight on 8 November 2005 which is shown in

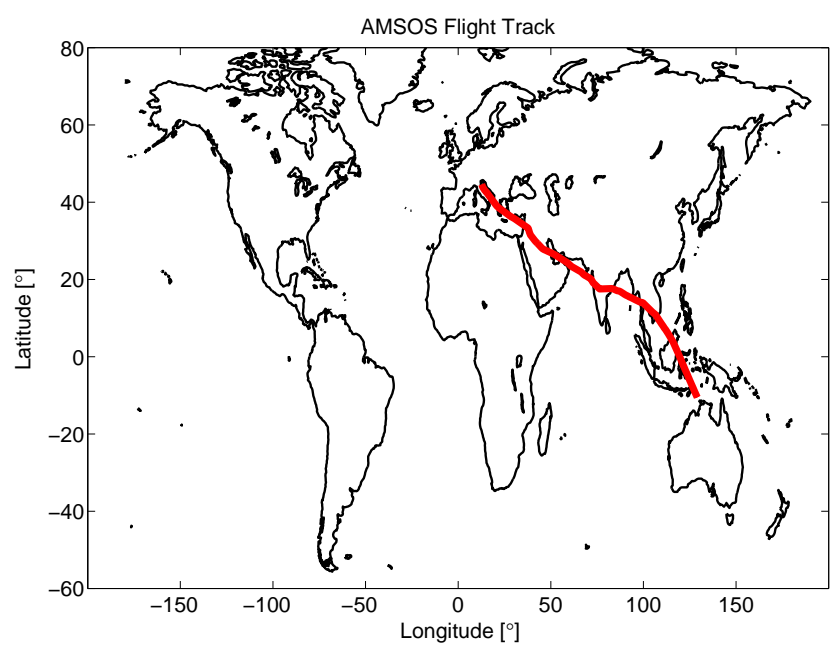

Fig. 4. AMSOS flight track Switzerland to Australia and back for the SCOUT-O3 Darwin campaign transfer flight in November 2005.
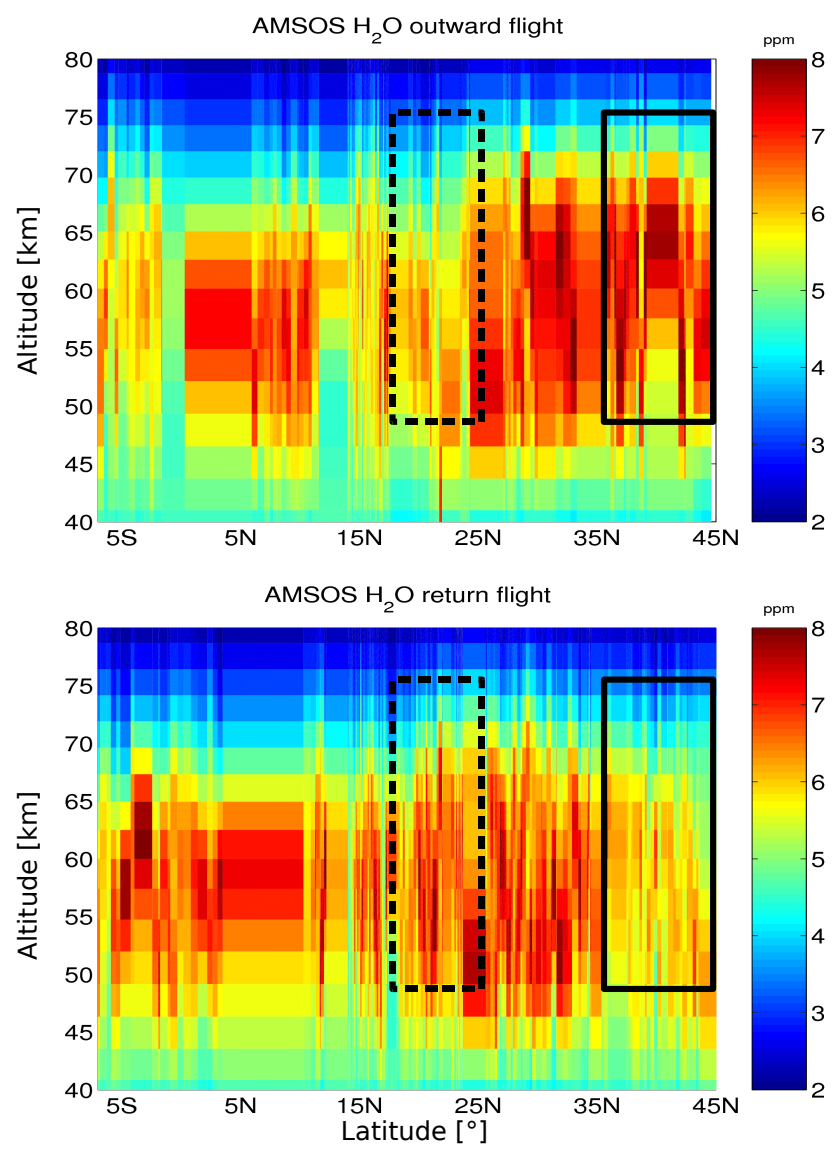

Fig. 5. Retrieved water vapor profiles as a function of latitude on the outward flight on top and the return flight below. The water vapor VMR varies between 3 and $8 \mathrm{ppm}$ and has its maximum usually around the stratopause. The solid rectangle highlights the significant differences on the outward and return flight above the Mediterranean whereas the dashed rectangle covers the situation above the Arabian Sea and India. 


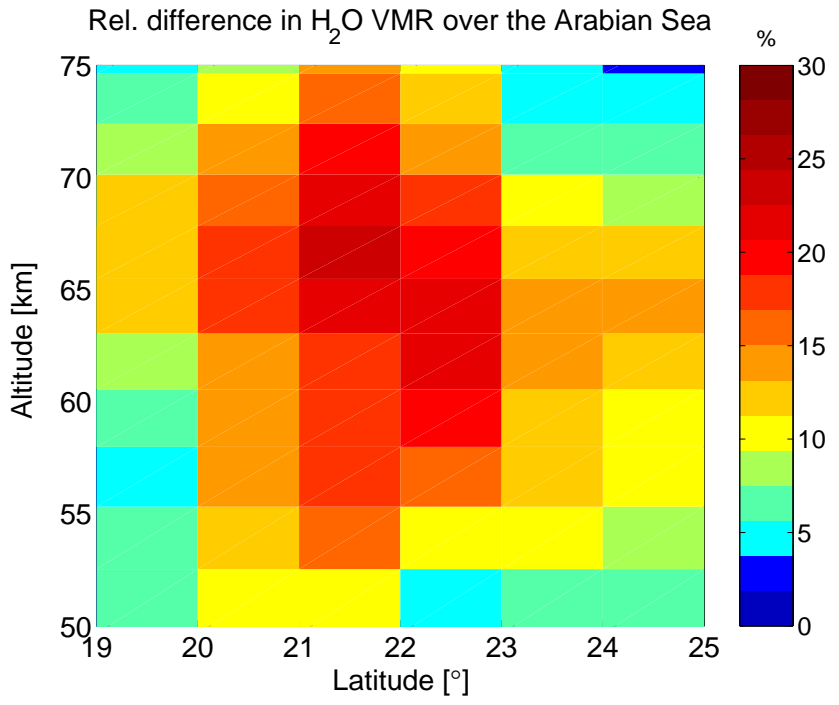

Fig. 6. The relative difference of return and outward flight $\mathrm{H}_{2} \mathrm{O}$ VMR over the Arabian Sea and India in the lower mesosphere. AMSOS measured up to $25 \%$ more water vapor on the return flight.

Fig. 6. On the other hand AMSOS measured up to $25 \%$ less at same altitudes on the return flight over the Mediterranean, see Fig. 7. The plotted relative differences are the differences of the return and outward flight with respect to the outward flight. In the following sections we will first describe the used trajectory model and then discuss the measured differences above the Arabian Sea and the Mediterranean.

\subsection{Trajectory model}

A mesospheric water vapor enhancement of this extent is possibly due to transport of airmasses from regions of higher $\mathrm{H}_{2} \mathrm{O}$ VMR, since there are no strong sources of water vapor in the lower mesosphere. Analysis of horizontal air parcel trajectories is utilized for verification of this assumption and for a more detailed understanding. Normally we use the Goddard Automailer (Schoeberl and Sparling, 1994) trajectory model (http://code916.gsfc.nasa.gov/Data_services/ automailer/index.html), but unfortunately it does not provide mesospheric trajectories based on wind data from the European Center of Medium Range Weather Forecast (ECMWF) which are possibly the best estimates for this altitude region. ECMWF wind fields are available up to an altitude of $65 \mathrm{~km}$ in November 2005. By means of a simple trajectory model TomTOM (Tom's TrajectOry Model), developed by one of the authors, we calculate trajectories. The model is set up in a Matlab code and interpolates directly ECMWF wind data on the exact air parcel location. Isentropic motion is assumed and we use a one hour time step before a new velocity vector is calculated. Comparison to the HYSPLIT (NOAA) model (Draxler and Hess, 1998) and Goddard Automailer showed an agreement of better than $200 \mathrm{~km}$ for 3

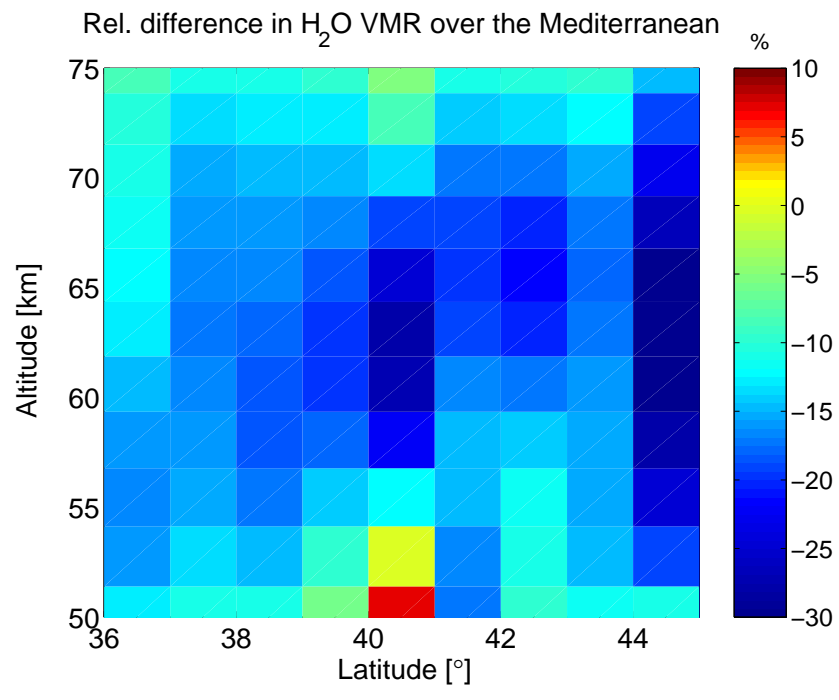

Fig. 7. The relative difference of return and outward flight in $\mathrm{H}_{2} \mathrm{O}$ VMR over the Mediterranean Sea in the lower mesosphere. There were 2 weeks between both measurements in November 2005. AMSOS measured up to $25 \%$ less water vapor on the return flight.

day trajectories at $20 \mathrm{~km}$ altitude. No comparison could be made for mesospheric altitudes. ECMWF values, which are spread on a $1.125^{\circ}$ grid are stored in our Institute's MySQL database with user-friendly search options. Matlab accesses directly these data and calculates trajectories with the equation of motion. Matlab provides the trajectory datafile and a geographic map with the trajectory as output. A flow chart of TomTOM is sketched in Fig. 8. An efficient handling of large data fields is important for trajectory models. Our experience indicates that MySQL is ideal for the extensive administrative and search tasks connected with trajectory calculations.

\subsection{Enhancement above the Arabian Sea and India}

Three days backward trajectories were calculated for both flight tracks of outward and return flight over the Arabian Sea. The outward flight took place on 8 November and the return flight one week later on 15 November. Consequently air parcel trajectories were calculated back to the starting days 5th and 12th of November for the $2700 \mathrm{~K}$ isentropic surface which corresponds approximately to an altitude of $60 \mathrm{~km}$. The results are shown in Figs. 9 and 10. There is in fact a huge difference in the trajectories as there is one in $\mathrm{H}_{2} \mathrm{O}$ VMR. For the outward flight air parcels came in an eastward current across the Atlantic Ocean and northern Africa whilst one week later the wind direction changed and parcels moved on a northward-westward current and started mainly over northern India, Nepal and Thailand. This change in trajectories shows the strong dynamical variability of the lower mesosphere over India where a change of the horizontal wind direction occurred. Fig. 3 shows a measured global map of mesospheric water vapor at $60 \mathrm{~km}$ from the 


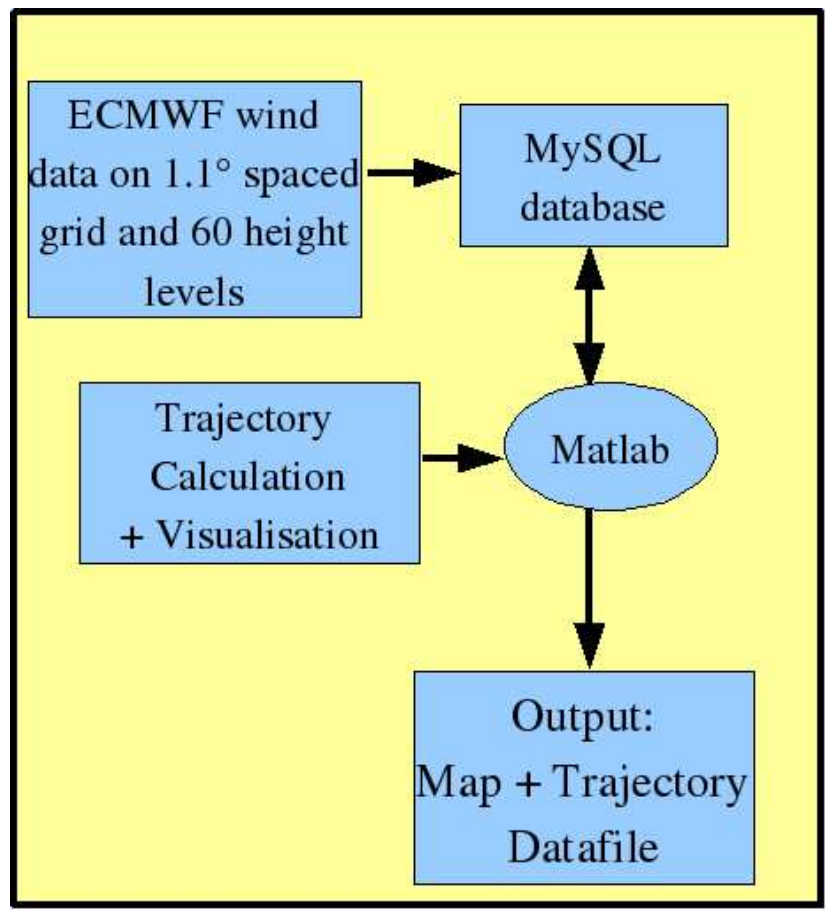

Fig. 8. Tom's TrajectOry Model TomTOM based on ECMWF wind data. Trajectory calculation is implemented in a Matlab routine which takes directly the corresponding ECMWF wind data out of the institute's MySQL database.

Aura/MLS satellite experiment (http://mls.jpl.nasa.gov/data/ gallery.php). It confirms that there was about $20 \%$ less water vapor in the region above the Atlantic Ocean on 5 November around $21 \mathrm{~N}$ between the Cape Verde Islands and the Canary Islands, where the air parcels started, compared to one week later over northern India and Nepal, which is shown by the MLS Fig. 11 of 12 November. Relatively dry air masses of $6.2 \mathrm{ppm}$ were transported to India from tropical regions near Cape Verde during the outward flight, whereas one week later more humid air of $7.4 \mathrm{ppm}$ was transported into the same region passing above Nepal. The big difference is that the air parcels calculated backward for 8 November were in a stronger southward directed meridional wind and were able to reach strong zonal westerlies, such as those visible in Fig. 2, and hence travelled a much longer distance in 3 days than the parcels calculated for 15 November. On 15 November the meridional wind at $60 \mathrm{~km}$ along the flight track was northward.

\subsection{Decrease above the Mediterranean}

A similar difference in lower mesospheric water vapor was also measured over the Mediterranean. Fig. 7 shows that there was about $20 \%$ more water vapor during the outward flight on 4 November than during the return flight on 16 November. The same trajectory analysis is done for this

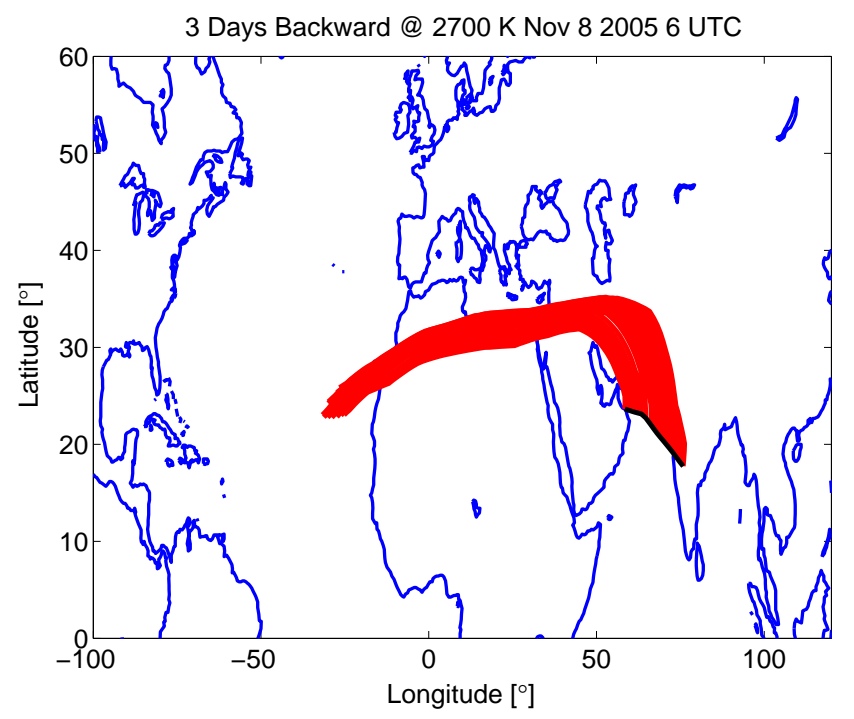

Fig. 9. Backward trajectories along the outward flight calculated on the $2700 \mathrm{~K}$ isentrope. The black line indicates the flight track from west to east. Parcels start on 5 November above the Atlantic Ocean and reach the black flight track on 8 November. The corresponding MLS $\mathrm{H}_{2} \mathrm{O}$ field is given in Fig. 3 for the starting time of the trajectories

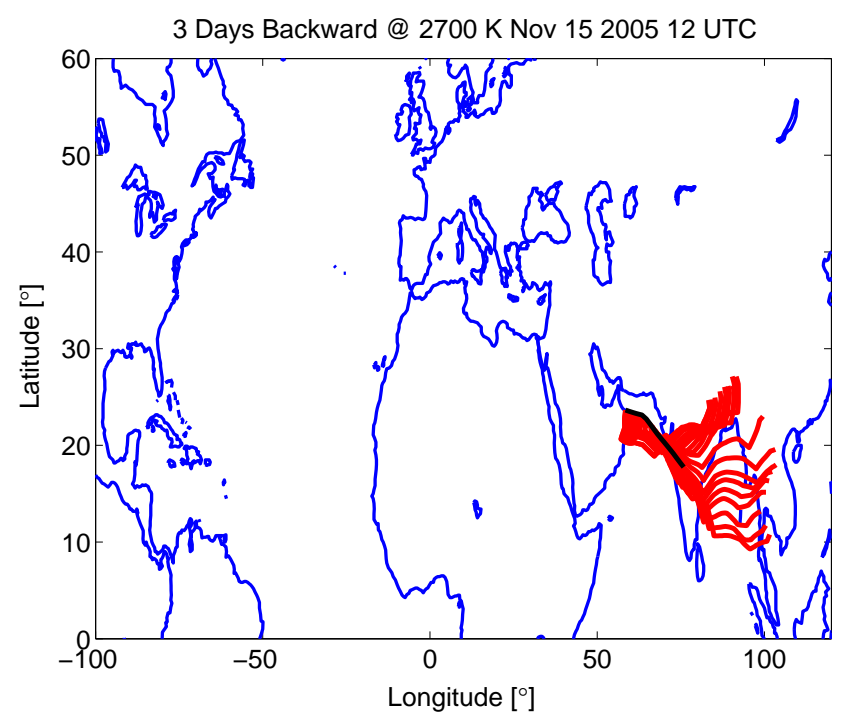

Fig. 10. Backward trajectories along the return flight calculated on the $2700 \mathrm{~K}$ isentrope. The black line indicates the flight track east to west. Parcels start on November 12 above northern India, Nepal and Thailand and reach the blue flight track on 15 November. The corresponding MLS $\mathrm{H}_{2} \mathrm{O}$ field is given in Fig. 11 for the starting time of the trajectories 

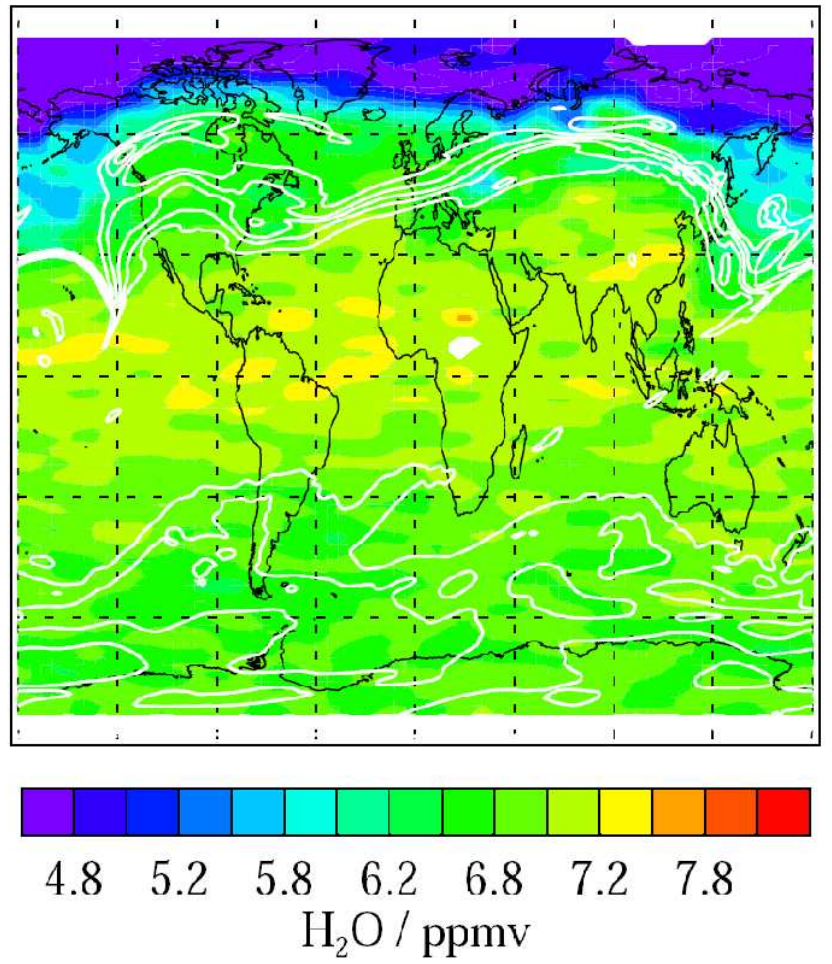

Fig. 11. Aura MLS water vapor at $60 \mathrm{~km}$ on 12 th November. Air parcels started in the yellow region over northern India and Nepal. Maps available on http://mls.jpl.nasa.gov/data/gallery.php.

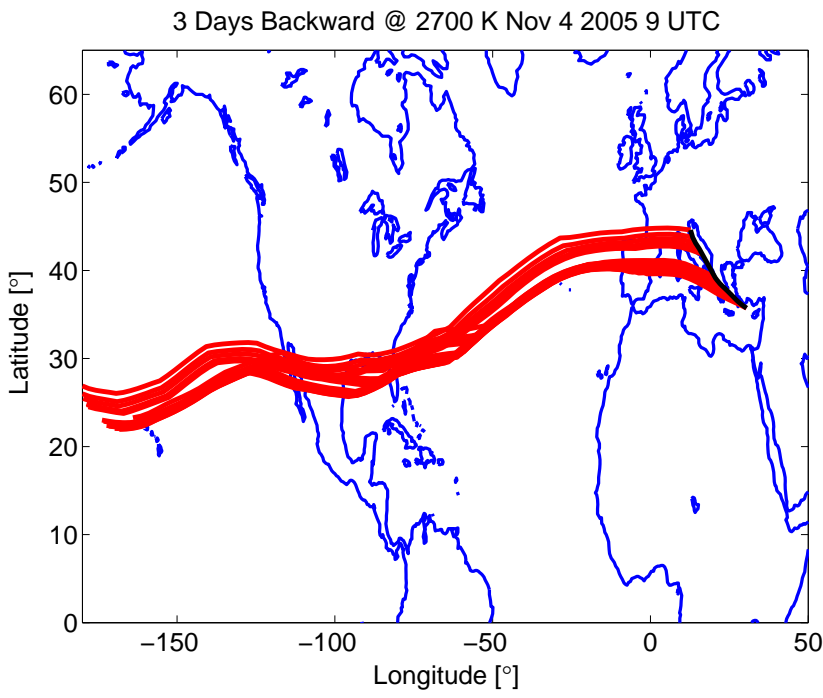

Fig. 12. Backward trajectories along the outward flight conducted on 4 November calculated on the $2700 \mathrm{~K}$ isentrope, which is approximately $60 \mathrm{~km}$. The black line indicates the flight track from north to south. The origin of the air parcels is more south than 12 days later shown in Fig. 13. he corresponding MLS $\mathrm{H}_{2} \mathrm{O}$ field is given in Fig. 14 for the starting time of the trajectories

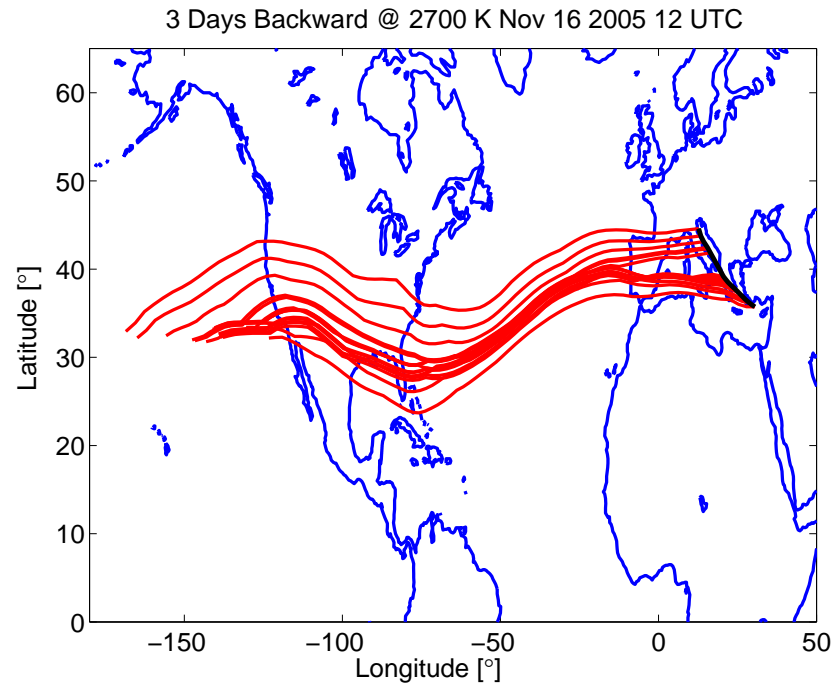

Fig. 13. Backward trajectories along the return flight conducted on 16 November calculated on the $2700 \mathrm{~K}$ isentrope. The black line indicates the flight track south to north. Trajectories pass more north to enter the United States in the beginning than 12 days before as shown on Fig. 10. The corresponding MLS $\mathrm{H}_{2} \mathrm{O}$ field is given in Fig. 15 for the starting time of the trajectories

situation. Three days backward trajectories were calculated along the flighttrack on the $2700 \mathrm{~K}$ isentrope, which corresponds approximately to $60 \mathrm{~km}$. Results are shown in Figs. 12 and 13. There is a considerable difference in the first part of the trajectories: During the outward flight air parcels moved between $22 \mathrm{~N}$ and $30 \mathrm{~N}$, which is $10^{\circ}$ more south than 12 days later, crossed Florida and the Atlantic Ocean. The trajectories for the return flight in Fig. 13 show that air parcels moved first northward entered the US around $40 \mathrm{~N}$ turned again southward and crossed the Atlantic Ocean similar to the air parcels calculated for the outward flight in Fig. 12. The sinusoidal structure of the trajectories in Fig. 13 is probably due to a planetary wave. A look on the Aura/MLS water vapor measurements reveals that there is a significant difference in mesospheric $\mathrm{H}_{2} \mathrm{O}$ VMR over the west coast of Mexico on 1 November in Fig. 14 and the west coast of the US on 13 November around $40 \mathrm{~N}$ in Fig. 15 where the air parcels passed through. Air parcels for the outward flight crossed Mexico in a region of about $6.4 \mathrm{ppm}_{2} \mathrm{O}$ as visible in Fig. 14, whilst 12 days later around $40 \mathrm{~N}$ on the East-coast of the US volume mixing ratios of about $5.5 \mathrm{ppm}$ are found, see Fig. 15. This is a difference of approximately $16 \%$ and explains qualitatively the observed variation of $\mathrm{H}_{2} \mathrm{O}$ VMR between both flight tracks over the Mediterranean Sea.

\subsection{Latitudinal gradient}

A mesospheric latitudinal gradient is clearly visible above $65 \mathrm{~km}$ during the outward flight shown in Fig. 5. The ratio drops from values of about $6.5 \mathrm{ppm}$ north of $23^{\circ} \mathrm{N}$ to 


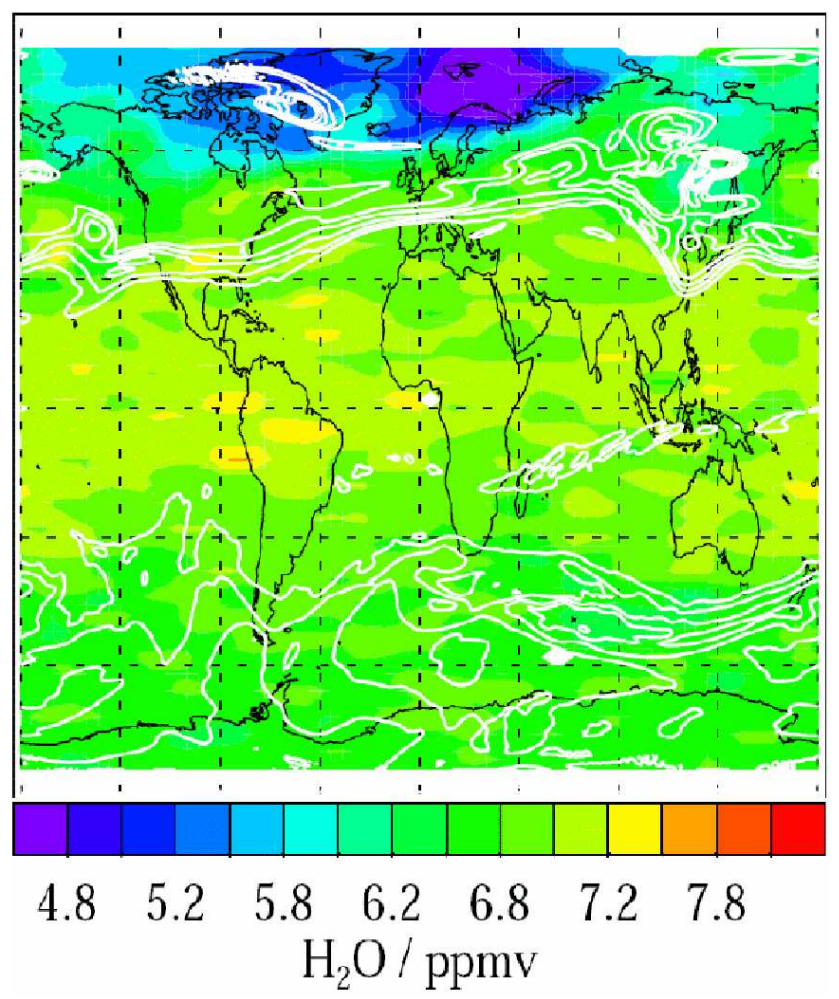

Fig. 14. Aura MLS water vapor at $60 \mathrm{~km}$ on November 1st. Air parcels started in the light green region of about $6.4 \mathrm{ppm}$ on the west coast of Mexico. Maps available on http://mls.jpl.nasa.gov/ data/gallery.php.

$5 \mathrm{ppm}$ south of it. The reason for this abrupt change is the time gap of 4 days between the measurements north of $23 \mathrm{~N}$ and south of it. In this time air masses of lower $\mathrm{H}_{2} \mathrm{O}$ VMR moved into this area which is visible in MLS plots at $60 \mathrm{~km}$ altitude (plots to find on the webpage http://mls. jpl.nasa.gov/data/gallery.php). It might also be explained by the so called tropical pipe model, with dynamical barriers between low and middle latitudes, (Plumb, 1996). Figs. 3, 11,14 and 15 show a separation of the tropical regions with higher $\mathrm{H}_{2} \mathrm{O}$ VMR (light green) to the extratropical region with lower VMR (dark green). Currently studies for lower mesospheric transport are rare and the $\mathrm{H}_{2} \mathrm{O}$ radiometers AMSOS and MIAWARA (Deuber et al., 2005) operated by our Institute of Applied Physics in Bern (Switzerland) provide valuable information about dynamical processes in the lower mesosphere. This is an important issue as dynamics directly affects chemistry of the middle atmosphere and vice versa (Sonnemann and Grygalashvyly, 2003).

\section{Conclusions}

This study is an example of how water vapor can be used as a tracer for lower mesospheric air mass transport. The analysis of local water vapor measurements with an economic trajec-

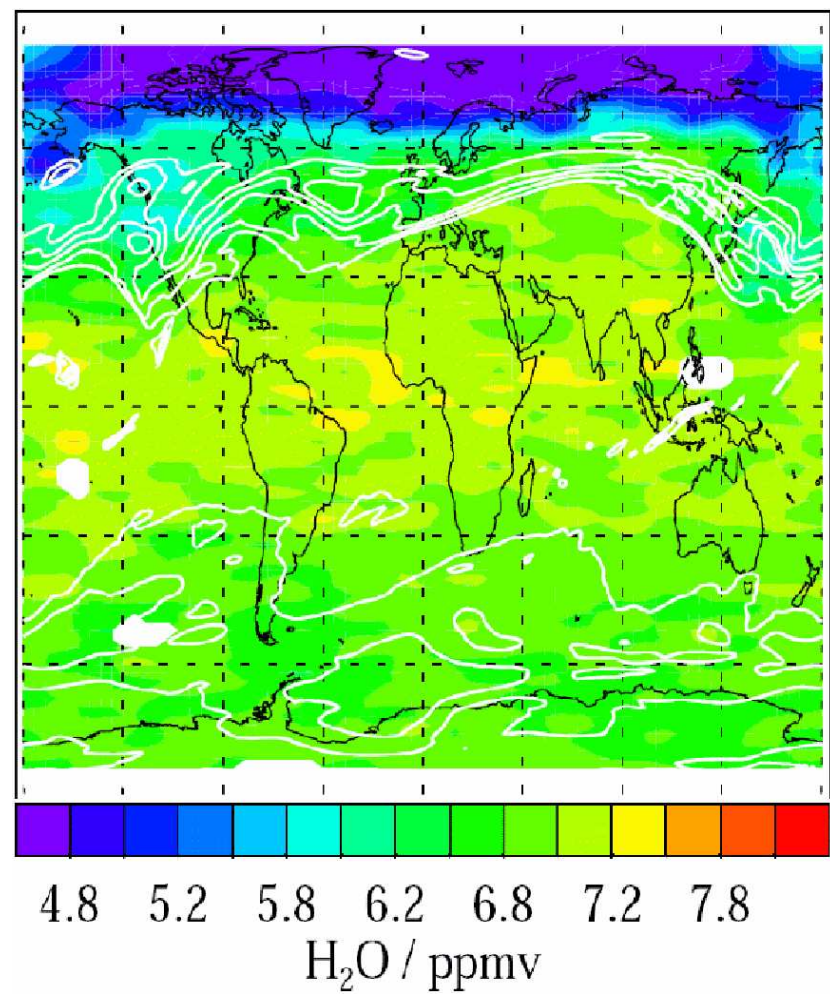

Fig. 15. Aura MLS water vapor at $60 \mathrm{~km}$ on 13 th November. Air parcels crossed the blue region of about $5.5 \mathrm{ppm}$ on the west coast of the United States. Maps available on http://mls.jpl.nasa.gov/data/ gallery.php.

tory model can provide a detailed picture of middle atmospheric water vapor and dynamic influences. The measured water vapor enhancement above the Arabian Sea and India on the return flight was due to airmass transport from a different region. The change in air parcel trajectories is due to the changing horizontal wind direction which is around $20 \mathrm{~N}$ in November 2005. During the outward flight the mesospheric wind direction was eastward over Northern India whilst one week later it was slightly westward. The measured decrease in the section of the flight above the Mediterranean is also due to transport of air from different regions. The relatively dry air measured on the return flight passed through a dry region on the west coast of the United States. Twelve days before, air parcels traveled further south in more humid air. Hence our assumption of horizontal transport responsible for the significant changes in mesospheric $\mathrm{H}_{2} \mathrm{O}$ VMR is confirmed by Aura/MLS measurements and the use of a trajectory model run with ECMWF winds. Finally microwave remote sensing has prooven to be suitable for the study of atmospheric dynamics and composition changes. Presently not much is known about transport processes in the lower mesosphere. With the extension of the upper boundary of the ECMWF reanalysis model, calculation of realistic trajectories is possible, which we find in agreement with AMSOS 
and Aura/MLS observations of the variability of lower mesospheric water vapor. Recent studies by Hoppel et al. (2008) and Berger (2008) also show the progress which has been achieved in data assimilation and modeling of the middle atmosphere.

Acknowledgements. This work has been supported by the ECproject SCOUT-O3 under grant SBF Nr. 03.0352-2 and by the Swiss National Science Foundation under grant Nr. 200020$115882 / 1$. One of the authors (KH) was supported by the Oeschger Centre for Climate Change Research (OCCR). Thanks to the pilots of the Swiss Airforce Learjet, to Gloria Manney for the Aura/MLS glopal maps and to ECMWF for providing their analyses.

Edited by: P. Hartogh

\section{References}

Berger, U.: Modeling of middle atmosphere dynamics with LIMA, J. Atmos. Solar Terr. Phys., 70, 1170-1200, 2008.

Brasseur, G. P. and Solomon, S.: Aeronomy of the Middle Atmosphere: Chemistry and Physics of the Stratosphere and Mesosphere, Aeronomy of the Middle Atmosphere: Chemistry and Physics of the Stratosphere and Mesosphere, by G.P. Brasseur and S. Solomon. 2005 XII, 3rd rev. and enlarged ed. 1-40203284-6. Berlin, Springer, 644 pp., 2005.

Buehler, S., Eriksson, P., Kuhn, T., von Engeln, A., and Verdes, C.: ARTS, the Atmospheric Radiative Transfer Simulator, J. Quant. Spectrosc. Radiat. Transfer, 91, 65-93, 2005.

Deuber, B., Haefele, A., Feist, D. G., Martin, L., Kampfer, N., Nedoluha, G. E., Yushkov, V., Khaykin, S., Kivi, R., and Vömel, H.: Middle Atmospheric Water Vapour Radiometer - MIAWARA: Validation and first results of the LAUTLOS/WAVVAP campaign, J. Geophys. Res., 110, D13306, doi: 10.1029/2004JD005543, 2005.

Draxler, R. and Hess, G.: An overview of the Hysplit 4 modeling system for trajectories, dispersion and deposition, Aust. Met. Mag, 47, 295-308, 1998.

Eriksson, P., Jimenés, C., and Buehler, S. A.: Qpack, a general tool for instrument simulation and retrieval work, J. Quant. Spectrosc. Radiat. Transfer, 91, 47-64, doi:10.1016/j.jqsrt.2004.05. 050, 2005.

Feist, D. G., Geer, A. J., Müller, S., and Kämpfer, N.: Middle atmosphere water vapour and dynamical features in aircraft measurements and ECMWF analyses, Atmos. Chem. Phys., 7, 52915307, 2007,

http://www.atmos-chem-phys.net/7/5291/2007/.

Flury, T., Hocke, K., Müller, S., and Kämpfer, N.: First measurements of lower mesospheric wind by airborne microwave radiometry, Geophys. Res. Lett., 35, L19802, doi:10.1029/ 2008GL034663, 2008.
Hoppel, K. W., Baker, N. L., Coy, L., Eckermann, S. D., McCormack, J. P. Nedoluha, G. E., and Siskind, E.: Assimilation of stratospheric and mesospheric temperatures from MLS and SABER into a global NWP model, Atmos. Chem. Phys., 8, 6103-6116, 2008, http://www.atmos-chem-phys.net/8/6103/2008/.

Müller, S., Kämpfer, N., Feist, D., Haefele, A., Milz, M., Sitnikov, N., Schiller, C., Kiemle, C., and Urban, J.: Validation of stratospheric water vapour measurements from the airborne microwave radiometer AMSOS, Atmos. Chem. Phys., 8, 31693183, 2008, http://www.atmos-chem-phys.net/8/3169/2008/.

Müller, S. C., Murk, A., Monstein, C., and Kämpfer, N.: Intercomparison of Digital Fast Fourier Transform and Accousto Optical spectrometers for microwave radiometry of the atmosphere, IEEE T. Geosci. Rem. Sens., in press, 2008.

Plumb, R. A.: A "tropical pipe" model of stratospheric transport, J. Geophys. Res., 101, 3957-3972, doi:10.1029/95JD03002, 1996.

Rodgers, C. D.: Inverse Methods for Atmospheric Sounding: Theory and Practice, vol. 2 of Series on atmospheric, oceanic and planetary physics, World Scientific Publishing Co. Pte. Ltd., P.O. Box 128, Farrer Road, Singapore 912805, 2000.

Schoeberl, M. and Sparling, L.: Trajectory Modelling, Diagnostic Tools in Atmospheric Physics, Proc. S. I. F. Course CXVI, 1994.

Shepherd, T. G.: The middle atmosphere, J. Atmos. Sol.-Terr. Phys., 62, 1587-1601, 2000.

Sonnemann, G. R. and Grygalashvyly, M.: The zonal wind effect on the photochemistry within the mesosphere/mesopause region, Adv. Space Res., 32, 719-724, doi:10.1016/S0273-1177(03) 00406-X, 2003.

Vasic, V., Feist, D. G., Müller, S., and Kämpfer, N.: An airborne radiometer for stratospheric water vapor measurements at $183 \mathrm{GHz}$, IEEE T. Geosci. Rem. Sens., 43, 1563-1570, doi: 10.1109/TGRS.2005.846860, 2005.

Waters, J. W., Froidevaux, L., Harwood, R. S., Jarnot, R. F., Pickett, H. M., Read, W. G., Siegel, P. H., Cofield, R. E., Filipiak, M. J., Flower, D. A., Holden, J. R., Lau, G. K., Livesey, N. J., Manney, G. L., Pumphrey, H. C., Santee, M. L., Wu, D. L., Cuddy, D. T., Lay, R. R., Loo, M. S., Perun, V. S., Schwartz, M. J., Stek, P. C., Thurstans, R. P., Boyles, M. A., Chandra, K. M., Chavez, M. C., Chen, G.-S., Chudasama, B. V., Dodge, R., Fuller, R. A., Girard, M. A., Jiang, J. H., Jiang, Y., Knosp, B. W., Labelle, R. C., Lam, J. C., Lee, A. K., Miller, D., Oswald, J. E., Patel, N. C., Pukala, D. M., Quintero, O., Scaff, D. M., Vansnyder, W., Tope, M. C., Wagner, P. A., and Walch, M. J.: The Earth Observing System Microwave Limb Sounder (EOS MLS) on the Aura Satellite, IEEE T. Geosci. Rem. Sens., 44, 1075-1092, doi: 10.1109/TGRS.2006.873771, 2006. 